\title{
Severity of Chronic Obstructive Pulmonary Disease and Its Relationship to Lung Cancer Prognosis after Surgical Resection*
}

\author{
Yasuo Sekine $^{1}$ Hidemi Suzuki $^{1}$ Yoshito Yamada $^{2}$ \\ ${ }^{1}$ Department of Thoracic Surgery, Tokyo Women's Medical University, \\ Yachiyo Medical Center, Yachiyo, Japan \\ 2 Department of Thoracic Surgery, Graduate School of Medicine, Chiba \\ University, Chiba, Japan
}

\author{
Eitetsu Koh ${ }^{1}$ Ichiro Yoshino ${ }^{2}$
}

Address for correspondence Yasuo Sekine, MD, PhD, Department of Thoracic Surgery, Tokyo Women's Medical University, Yachiyo Medical Center, 477-96 OwadaShinden, Yachiyo, Chiba 276-8524, Japan (e-mail: ysekine@tymc.twmu.ac.jp).

Thorac Cardiovasc Surg 2013;61:124-130.

\section{Introduction}

Lung cancer and chronic obstructive pulmonary disease (COPD) are common fatal diseases. Patients with lung cancer who also have COPD are frequently deemed inoperable because of low cardiopulmonary reserve. Preoperative evaluation and risk stratification of patients undergoing lung resection include pulmonary function testing, arterial blood

${ }^{*}$ This paper was presented at the 54th Annual Meeting of the Thomas L. Petty Aspen Lung Conference in Colorado, USA, 2011.

received

September 2, 2011

accepted after revision

November 21, 2011

published online

April 25, 2012

gas analysis, exercise testing, and split perfusion-ventilation radionuclide scanning. ${ }^{1,2}$

Pulmonary complications after lung cancer surgery are major causes of morbidity for patients with COPD. ${ }^{3,4}$ Pulmonary resection decreases the already limited respiratory reserve and causes hypoventilation, hypoxia, hypercapnia, and retention of secretions, which can lead to respiratory failure, ${ }^{5}$ and poor short-term survival and quality of life (QOL). However, the effects of different degrees of COPD severity on short- and long-term survival have not been well studied. In particular, the risk of lung cancer recurrence in patients with COPD has been insufficiently studied.

(c) 2013 Georg Thieme Verlag KG Stuttgart · New York
DOI http://dx.doi.org/ 10.1055/s-0032-1304543. ISSN 0171-6425. 
Studies evaluating risk factors for postoperative complications and survival in patients with COPD have been published. ${ }^{5,6}$ However, the prevalences of different types of complications and their association with long-term survival of lung cancer patients with COPD have not been determined, especially for patients with postoperative pulmonary complications, in whom compromised lung function affects survival as well as quality of life.

The purpose of this study was to: (a) determine the prevalences of various types of postoperative complications in nonsmall cell lung cancer patients undergoing curative surgery in the various stages of COPD; (b) assess the impact of COPD on long-term survival of these patients; and (c) enumerate the causes of death in our patient population.

\section{Patients and Methods}

The study was approved by the Institutional Review Board of our hospital. Patient-informed consent was waived because this was a retrospective study. The medical records of 1,461 consecutive patients with lung cancer who underwent pulmonary resection between January 1990 and April 2005 were retrospectively reviewed. Data were collected from our institutional cancer registry database and from patient follow-up medical visits, and consisted of information on preoperative patient characteristics, disease status, operative procedures, postoperative complications, pathologic diagnosis, and follow-up examinations. The data were collected at the time of hospital discharge and from outpatient charts in a prospective manner.

Of the 1,461 patients, 363 (24.8\%) had been diagnosed with COPD. There were 89 patients with mild, 238 with moderate, and 36 with severe COPD, based on spirometric criteria of the Global Initiative for Chronic Obstructive Lung Disease (GOLD) as follows ${ }^{7}$ : (1) non-COPD: forced expiratory volume in 1 second (FEV1)/forced vital capacity (FVC) $\geq 70 \%$, (2) mild COPD: FEV1/FVC $<70 \%$ and FEV $1 \geq 80 \%$ predicted, (3) moderate COPD: FEV1/FVC $<70$ and 50\% $\leq$ FEV1 $<80 \%$ predicted, (4) severe COPD: FEV1/FVC $<70$ and 30\% $\leq$ FEV1 $<50 \%$ predicted. The patients with mild to severe COPD constituted the COPD groups. All participants were involved perioperatively in a pulmonary rehabilitation program based on the severity of COPD.

Preoperative evaluation for all patients also included a detailed medical history, physical examination, blood and urine examinations, and a 12-lead electrocardiogram (ECG). Incentive spirometry and nebulization with distilled water with or without a bronchodilator were routinely encouraged to enhance lung expansion and airway clearance $\sim 1$ week before and after the surgery. Postoperative morbidities included bacterial pneumonia (confirmed by infiltrative shadows on chest X-ray, positive sputum culture, body temperature $\geq 37.5^{\circ} \mathrm{C}$ and white blood cell count $>10,000 / \mu \mathrm{L}$ ); acute interstitial pneumonia (AIP) (aggravation of dyspnea on exertion, deterioration of arterial blood gases, and diffuse interstitial abnormalities compatible with acute interstitial pneumonia); mechanical ventilation $\geq 3$ days, bronchial stump dehiscence; empyema (positive bacterial infection of pleural effusion); tracheostomy; and postoperative home oxygen therapy (HOT) for patients with $\mathrm{PaO}_{2}<60$ torr on exercise at the time of hospital discharge.

After the hospital discharge, patients visited our outpatient clinic regularly every 1 to 6 months, unless there was a tumor recurrence or any other problem. Tumor recurrence or metastasis was routinely evaluated by chest computed tomography (CT), brain magnetic resonance imaging (MRI), 2[18F]fluoro-2-deoxy-D-glucose positron emission tomography (FDG-PET), bone scintigraphy, and several serum tumor markers every 6 to 12 months. When patients returned to referring doctors or were referred to other doctors, the status of the patient and causes of death, if death occurred, were confirmed by mail or phone with the patient, patient's family or referring doctors every 2 years. Overall and diseasespecific survivals were analyzed for each patient group.

\section{Statistical Analysis}

Data were analyzed using Stat View version 5.0 (Statistical Analysis Systems; Cary, North Carolina, United States). To compare differences between the four groups, TukeyKramer's multiple comparison procedure was used to analyze continuous variables, and the $\chi^{2}$ test used for categorical variables. Survival curves were estimated using the KaplanMeier method, and differences in survival times between the four groups were calculated by the log-rank test. Cox's proportional hazards model was used to identify prognostic factors.

\section{Results}

\section{Preoperative Patient Characteristics}

Preoperative patient characteristics are summarized in -Table 1. Males and positive smoking history were more predominant in the mild to severe COPD groups than in the non-COPD group. Values for FVC, \%FVC, FEV1, and FEV1/FVC were significantly lower in the mild to severe COPD groups than in the non-COPD group $(p<0.05)$. $\mathrm{PaO}_{2}$ values in the nonCOPD and mild COPD groups were significantly higher than values in the moderate and severe COPD groups $(p<0.05)$.

Perioperative characteristics are listed in - Table 2. Pneumonectomy was performed in six patients of the severe COPD group despite severe pulmonary dysfunction because in those patients, the main bronchus was obstructed with tumor, and it was thought that the reduction in pulmonary function would be minimal even after pneumonectomy. Adenocarcinoma was predominant in the non-COPD and mild COPD groups, whereas squamous cell carcinoma was predominant in the moderate and severe COPD groups. Advanced cancer was more frequent in relation to the severity of COPD $(p<0.0001)$.

\section{Postoperative Morbidity and Mortality}

Postoperative pulmonary complications and mortality are summarized in -Table 3. The frequencies of all specific pulmonary complications and 30-day mortality were significantly higher in the severe COPD group than in any other 
Table 1 Preoperative patient characteristics

\begin{tabular}{|c|c|c|c|c|c|}
\hline \multirow[t]{2}{*}{ Characteristics } & Non-COPD & Mild COPD & Moderate COPD & Severe COPD & \multirow[t]{2}{*}{$p$-Value } \\
\hline & $(n=1,098)$ & $(n=89)$ & $(n=238)$ & $(n=36)$ & \\
\hline Gender male, $n(\%)$ & $656(59.7)$ & $79(88.8)$ & $220(92.4)$ & $36(100)$ & $<0.0001$ \\
\hline Gender Female & 442 & 10 & 18 & 0 & \\
\hline Age $(y)^{a}$ & $62.5 \pm 10.3$ & $69.1 \pm 7.7^{b}$ & $67.6 \pm 7.1^{b}$ & $67.9 \pm 5.7^{\mathbf{b}}$ & \\
\hline $\operatorname{BMI}\left(\mathrm{kg} / \mathrm{m}^{2}\right)^{\mathrm{a}}$ & $22.5 \pm 3.2$ & $22.3 \pm 2.4$ & $21.9 \pm 3.0^{b}$ & $21.1 \pm 3.4$ & \\
\hline PSH, $n(\%)$ & $666(60.7)$ & $80(89.9)$ & $225(94.5)$ & $36(100)$ & $<0.0001$ \\
\hline Smoking index (pack-year) & $46.4 \pm 28.0$ & $57.6 \pm 33.3$ & $55.5 \pm 31.1$ & $53.5 \pm 21.5$ & \\
\hline \multicolumn{6}{|l|}{ Pulmonary function tests ${ }^{\mathrm{a}}$} \\
\hline FVC (L) & $2.90 \pm 0.76$ & $3.59 \pm 0.71^{b}$ & $2.98 \pm 0.56^{\mathrm{b}, \mathrm{c}}$ & $2.39 \pm 0.41$ & \\
\hline$\% F V C(\%)$ & $97.1 \pm 18.0$ & $114.0 \pm 12.7^{b}$ & $92.4 \pm 12.8^{b, c}$ & $73.4 \pm 10.4^{\mathrm{b}, \mathrm{c}}$ & \\
\hline FEV1 (L) & $2.38 \pm 2.51$ & $2.37 \pm 0.47$ & $1.85 \pm 0.36^{\mathbf{b}, \mathbf{c}}$ & $1.24 \pm 0.25^{\mathrm{b}, \mathrm{c}}$ & \\
\hline \%FEV1 (\%) & $90.0 \pm 17.6$ & $90.0 \pm 8.7$ & $66.3 \pm 8.3^{\mathrm{b}, \mathrm{c}}$ & $43.0 \pm 6.7^{\mathbf{b}, \mathbf{c}}$ & \\
\hline FEV1/FVC (\%) & $80.0 \pm 6.1$ & $65.8 \pm 3.7^{\mathrm{a}}$ & $62.2 \pm 6.2^{\mathrm{b}, \mathrm{c}}$ & $52.0 \pm 10.1^{\mathrm{b}, \mathrm{c}}$ & \\
\hline $\mathrm{PaO}_{2}$ (torr) & $88.0 \pm 9.6$ & $86.7 \pm 9.3$ & $84.1 \pm 9.3^{b}$ & $82.1 \pm 11.6^{\mathrm{b}}$ & \\
\hline $\mathrm{PaCO}_{2}$ (torr) & $41.1 \pm 3.7$ & $40.7 \pm 3.2$ & $40.6 \pm 3.5$ & $40.6 \pm 3.8$ & \\
\hline
\end{tabular}

Abbreviations: BMI, body mass index; COPD, chronic obstructive pulmonary disease; FEV1, forced expiratory volume in 1 second; forced vital capacity; $\mathrm{PSH}$, positive smoking history.

${ }^{\mathrm{a}}$ Data are presented as mean \pm SD.

${ }^{\mathrm{b}} p<0.05$ for Tukey-Kramer's multiple comparison with data from the non-COPD group.

${ }^{c} p<0.05$ for Tukey-Kramer's multiple comparison with data from the mild COPD group.

group. Pneumonia occurred more frequently in the mild to severe COPD groups than in the non-COPD group $(p<0.0001)$. The causes of 30-day mortality included empyema with bronchial fistula $(n=2)$, bacterial pneumonia $(n=1)$, interstitial pneumonia $(n=1)$, empyema $(n=1)$, myocardial infarction $(n=1)$, massive bleeding $(n=1)$, brain infarction $(n=1)$, deteriorating interstitial pneumonia $(n=1)$, and acute respiratory distress syndrome $(n=2)$.

\section{Survival Analyses}

-Fig. 1 shows overall survival following the surgery. Cumulative 5-year survival rates of the four groups were $61.5 \%$ (nonCOPD), 50.2\% (mild COPD), 55.3\% (moderate COPD), and 25.1\% (severe COPD) $(p<0.0001)$. In patients with pathological stage IA disease, overall 5-year survival rates were $89.0 \%$ (non-COPD), 52.5\% (mild COPD), 81.1\% (moderate COPD), and 57.9\% (severe COPD) $(p<0.0001,-$ Fig. 2 ). Although there was also a significant difference in survival rates in pathological stage IB patients ( $p=0.0038)$, there were no statistical differences in survival in stages IIA to IV. Although there was no significant difference in disease-specific survival for the entire study population ( $p=0.194$, - Fig. 3 ), patients with mild to severe COPD had significantly lower disease-specific survival rates than patients with non-COPD for stage IA ( $p<0.0001$, - Fig. 4). The 5-year disease-specific survival rates were $93.0 \%$ in the non-COPD, $60.8 \%$ in the mild COPD, $82.6 \%$ in the moderate COPD, and $85.7 \%$ in the severe COPD group.

\section{Multivariate Analyses of Risk Factors for Long-Term Overall Mortality}

We attempted to identify risk factors for long-term overall mortality. By univariate analysis, male gender, increased age, decreased BMI, positive smoking history, increased tumor size, pneumonectomy, squamous cell carcinoma, pathologic stage, FEV1/FVC, \% predicted FEV1, and severity of COPD were all significant factors $(p<0.001)$. By multivariate analysis, increased age, decreased BMI, positive smoking history, increased tumor size, pneumonectomy, squamous cell carcinoma, advanced pathologic stage, and severe COPD were identified as independent risk factors ( - Table 4 ).

\section{Discussion}

We previously reported that stage IA lung cancer patients with COPD had poorer long-term survivals compared with those without COPD, because they had higher rates of tumor recurrence and metastasis. ${ }^{8}$ In this current study, we extended patient selection from stage IA to all pathologic stages and divided patients into four groups based on the severity of COPD. It was confirmed that in more severe COPD, there were higher rates of postoperative complications and poorer longterm survival than in less severe COPD. Only survival rate of patients with mild COPD seemed to be relatively worse than that of patients with moderate COPD (statistically not significant in -Figs. 1 to 4 ). This may be due to the small number of patients with mild COPD. However, in patients with advanced lung cancer, COPD was not an important prognostic factor because of rapid disease progression.

COPD and lung cancer are closely related, and COPD is a significant risk factor for lung cancer development. Reports have shown that between 50 and $80 \%$ of patients diagnosed with lung cancer had pre-existing $\mathrm{COPD},{ }^{9,10}$ and that the prevalence of COPD in lung cancer varied from 8 to $50 \%{ }^{11,12}$ Furthermore, the prognosis for lung cancer patients with 
Table 2 Perioperative characteristics of lung cancer patients

\begin{tabular}{|c|c|c|c|c|c|}
\hline \multirow[t]{2}{*}{ Characteristics } & Non-COPD & Mild COPD & Moderate COPD & Severe COPD & \multirow[t]{2}{*}{$p$-Value } \\
\hline & $(n=1,098)$ & $(n=89)$ & $(n=238)$ & $(n=36)$ & \\
\hline \multicolumn{5}{|l|}{ Operation methods } & $<0.0001$ \\
\hline Pneumonectomy, $n$ (\%) & $56(5.1)$ & $14(15.7)$ & $13(5.5)$ & $6(16.7)$ & \\
\hline Lobectomy, $n$ (\%) & $980(89.3)$ & $71(79.8)$ & $205(86.1)$ & $26(72.2)$ & \\
\hline Segmentectomy/partial resection, $n(\%)$ & $52(4.7)$ & $4(4.5)$ & $18(7.6)$ & $4(11.1)$ & \\
\hline Tumor size $^{\mathrm{a}}(\mathrm{cm})$ (maximal diameter) & $3.2 \pm 1.9$ & $3.2 \pm 1.9$ & $3.7 \pm 2.0$ & $3.9 \pm 1.8$ & \\
\hline \multicolumn{5}{|l|}{ Histologic diagnoses, $n$ (\%) } & $<0.0001$ \\
\hline Ad & $736(67.6)$ & $55(62.5)$ & $98(41.4)$ & $10(27.8)$ & \\
\hline $\mathrm{Sq}$ & $239(21.9)$ & $30(34.1)$ & $113(47.7)$ & $23(63.9)$ & \\
\hline La & $46(4.2)$ & $2(2.3)$ & $15(6.3)$ & $2(5.6)$ & \\
\hline Others & $77(7.0)$ & $2(2.3)$ & $12(5.0)$ & $1(2.8)$ & \\
\hline \multicolumn{5}{|l|}{ Pathologic T status, $n$ (\%) } & 0.0001 \\
\hline 1 & $488(45.1)$ & $38(43.2)$ & $84(35.7)$ & $10(27.8)$ & \\
\hline 2 & $267(24.7)$ & $28(31.8)$ & $83(35.3)$ & $21(58.3)$ & \\
\hline 3 & $95(8.8)$ & $9(10.2)$ & $33(14.0)$ & $4(11.1)$ & \\
\hline 4 & $232(21.4)$ & $13(14.8)$ & $35(14.9)$ & $1(2.8)$ & \\
\hline \multicolumn{5}{|l|}{ Pathologic nodal status, $n(\%)$} & 0.789 \\
\hline 0 & $679(63.1)$ & $60(69.0)$ & $144(61.8)$ & $22(61.1)$ & \\
\hline 1 & $146(13.6)$ & & $10(11.5)$ & $42(18.0)$ & $6(16.7)$ \\
\hline 2 & $218(20.3)$ & $15(17.2)$ & $45(19.3)$ & $7(19.4)$ & \\
\hline 3 & $32(3.0)$ & & $2(2.3)$ & $2(0.9)$ & $1(2.8)$ \\
\hline \multicolumn{5}{|l|}{ Pathologic staging, $n(\%)$} & 0.0001 \\
\hline IA & $396(36.1)$ & $29(32.6)$ & $63(26.5)$ & $10(27.8)$ & \\
\hline $\mathrm{IB}$ & $132(12.0)$ & & $18(20.2)$ & $46(19.3)$ & $10(27.8)$ \\
\hline $\mathrm{IIA}$ & $47(4.3)$ & $1(1.1)$ & $8(3.4)$ & $0(0)$ & \\
\hline IIB & $99(9.0)$ & $8(9.0)$ & $34(14.3)$ & $7(19.4)$ & \\
\hline IIIA & $126(11.5)$ & $13(14.6)$ & $42(17.6)$ & $7(19.4)$ & \\
\hline IIIB & $230(21.0)$ & $15(16.9)$ & $33(13.9)$ & $1(2.8)$ & \\
\hline IV & $51(4.7)$ & $4(4.5)$ & $8(3.4)$ & $1(2.8)$ & \\
\hline
\end{tabular}

Abbreviations: Ad, adenocarcinoma; COPD, chronic obstructive pulmonary disease; La, large cell carcinoma; Sq, squamous cell carcinoma.

${ }^{\text {a }}$ Size was measured on resected specimen.

COPD is worse than for the patients without COPD because of inadequate cancer treatments and poorer pulmonary function and QOL. ${ }^{12}$ Sin et al summarized several series on the underlying causes of death in COPD patients. ${ }^{13}$ They reported that the main causes of death in those with mild or moderate COPD were lung cancer and cardiovascular diseases, whereas in those with more advanced COPD ( $<60 \%$ of predicted FEV1) respiratory failure was the predominant cause. This study has confirmed that poorer cancer survival was seen in patients with more advanced COPD than in non-COPD patients. This suggests that early detection of both COPD and lung cancer is needed for improving survival and maintaining QOL in patients with COPD. In this study, at least for patients who did not have severe COPD, standard lung cancer surgery could be performed with acceptable rates of postoperative complications.

Since Cooper et al reported favorable results after lung volume reduction surgery (LVRS) for severe emphysema, ${ }^{14}$ the functional limitation for lung cancer surgery in patients with COPD has also been extended. ${ }^{15}$ However, the effect of LVRS has been thought to be limited in patients with heterogeneous bullous emphysema with regard to expectations for improved exercise tolerance, better bronchial clearance, improved quality of life, and longer survival. ${ }^{16,17}$ In contrast, the effects of pulmonary resection on postoperative lung function for lung cancer patients with COPD have been clarified and 
128 Severity of Chronic Obstructive Pulmonary Disease Sekine et al.

Table 3 Postoperative complications and mortality

\begin{tabular}{|c|c|c|c|c|c|}
\hline \multirow[t]{2}{*}{ Characteristics } & Non-COPD & Mild COPD & Moderate COPD & Severe COPD & \multirow[t]{2}{*}{$p$-Value } \\
\hline & $(n=1,098)$ & $(n=89)$ & $(n=238)$ & $(n=36)$ & \\
\hline Characteristics & $(n=1,098)$ & $(n=89)$ & $(n=238)$ & $(n=36)$ & \\
\hline Pneumonia, $n(\%)$ & $47(4.2)$ & $9(10.1)$ & $31(13.0)$ & $5(13.9)$ & $<0.0001$ \\
\hline AIP, $n(\%)$ & $32(2.9)$ & $3(3.4)$ & $5(2.1)$ & $4(11.1)$ & 0.0316 \\
\hline Bronchial fistula, $n(\%)$ & $19(1.7)$ & $1(1.1)$ & $4(1.7)$ & $3(8.3)$ & 0.0332 \\
\hline Empyema, $n(\%)$ & $19(1.7)$ & $2(2.2)$ & $2(0.8)$ & $3(8.3)$ & 0.0171 \\
\hline Prolonged mech. vent., $n(\%)$ & $22(2.0)$ & $2(2.2)$ & $7(2.9)$ & $5(13.9)$ & 0.0001 \\
\hline HOT, $n(\%)$ & $6(0.5)$ & $0(0)$ & $2(0.8)$ & $0(0)$ & 0.7860 \\
\hline Tracheostomy, n (\%) & $67(0.6)$ & $12(13.5)$ & $24(10.1)$ & $9(25)$ & $<0.0001$ \\
\hline SVT, $n(\%)$ & $144(13.1)$ & $15(16.9)$ & $41(17.2)$ & $6(16.7)$ & 0.3138 \\
\hline 30-day mortality, n (\%) & $6(0.5)$ & $1(1.1)$ & $1(0.4)$ & $3(8.3)$ & $<0.0001$ \\
\hline
\end{tabular}

Abbreviations: AIP, acute interstitial pneumonia; COPD, chronic obstructive pulmonary disease; HOT, home oxygen therapy; prolonged mech. vent., prolonged mechanical ventilation $>3$ days; SVT, supraventricular tachycardia.

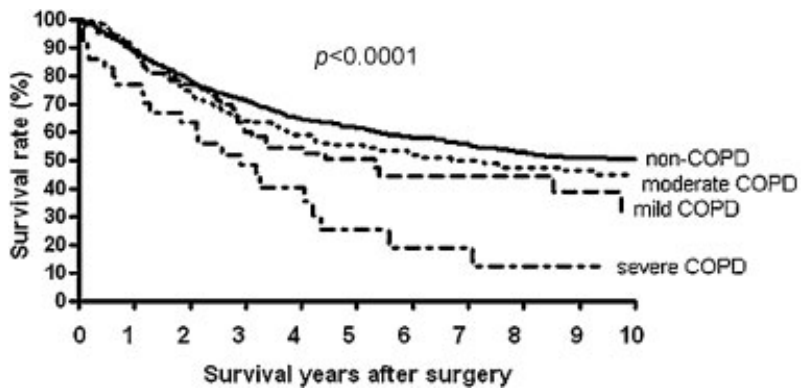

Fig. 1 Overall survival in all patients after pulmonary resection for lung cancer. The 5-year survivals for the non-COPD, mild, moderate, and severe COPD groups were $61.5,50.2,55.3$, and $25.1 \%$, respectively. A statistically significant difference was found according to COPD grade (log-rank $p<0.0001)$.

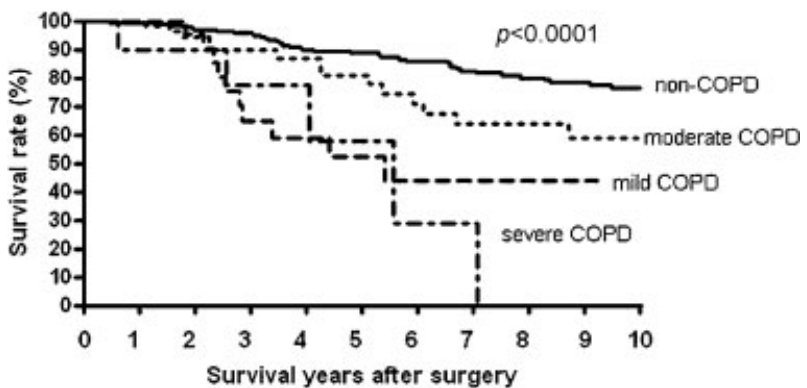

Fig. 2 Overall survival in patients with pathological stage IA cancer after pulmonary resection for lung cancer. The 5 -year survivals for the non-COPD, mild, moderate, and severe COPD groups were 89.0, 52.5, 81.0 , and $57.9 \%$, respectively. A statistically significant difference was found according to COPD grade (log-rank $p<0.0001)$.

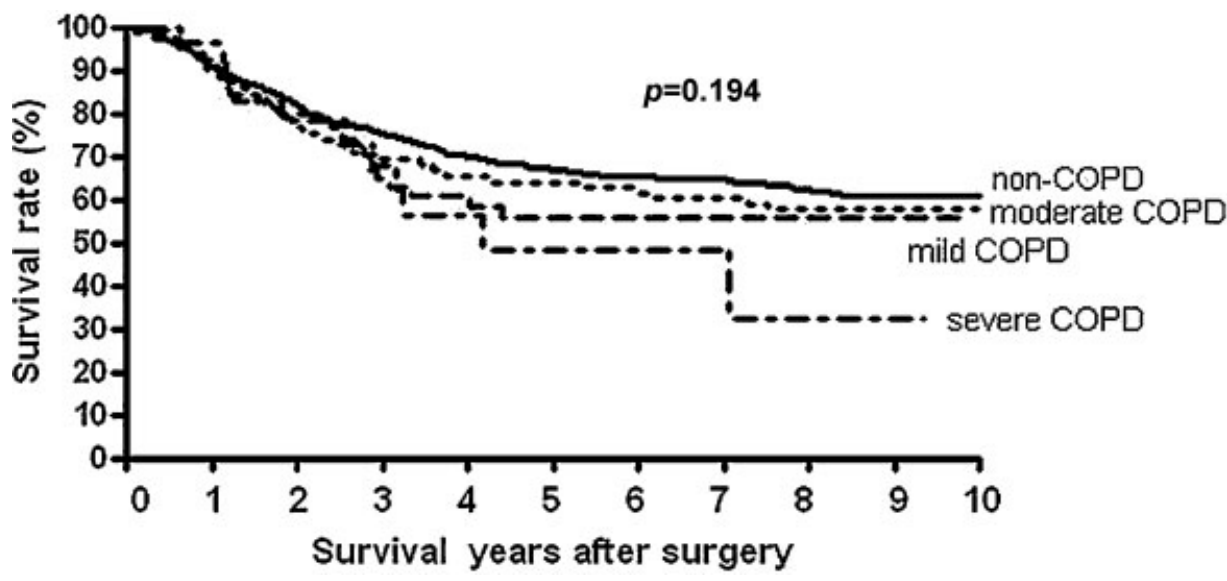

Fig. 3 Disease-specific survival in all patients after pulmonary resection for lung cancer. The 5 -year survivals for the non-COPD, mild, moderate, and severe COPD groups were $67.0,55.7,63.6$, and $48.4 \%$, respectively. No statistically significant difference was found according to COPD grade $(\log$-rank $p=0.1937)$. 


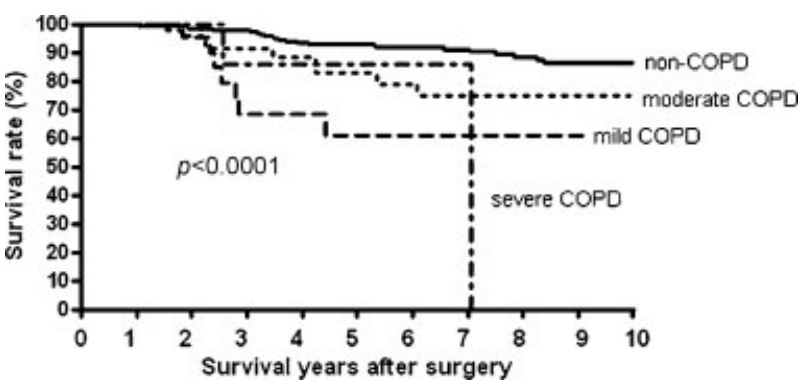

Fig. 4 Disease-specific survival in patients with pathological stage IA cancer after pulmonary resection for lung cancer. The 5 -year survivals for the non-COPD, mild, moderate, and severe COPD groups were $93.0,60.8,82.6$, and $85.7 \%$, respectively. A statistically significant difference was found according to COPD grade (log-rank $p<0.0001)$. actual postoperative function appeared to be better than predicted. ${ }^{18,19}$ Therefore, although predicted lung functions were not at preferred levels, we attempted as far as possible to perform standard lung cancer operations in patients with moderate to severe COPD.

By Cox's proportional hazards analyses, pneumonectomy was a significant negative risk factor for long-term survival. On the other hand, limited resection such as segmentectomy or partial resection was not a significant factor for reduced survival. It is well known that limited pulmonary resection did not confer improved perioperative morbidity, mortality, or late postoperative pulmonary function, but instead resulted in increased death and locoregional recurrence rates in patients with T1N0 nonsmall cell lung cancer. ${ }^{20}$ However,

Table 4 Multivariate analysis of risk factors for overall mortality by proportional hazards model

\begin{tabular}{|l|l|l|l|l|}
\hline Variables & $\chi^{2}$ test & Hazard ratio & $95 \%$ Cl & $p$-Value \\
\hline Gender (male) & 0.811 & 1.139 & $0.858-1.514$ & 0.3678 \\
\hline Age & 12.85 & 1.019 & $1.008-1.029$ & 0.0003 \\
\hline BMI & 13.00 & 0.946 & $0.917-0.975$ & 0.0003 \\
\hline Positive smoking history & 5.845 & 1.454 & $1.073-1.969$ & 0.0016 \\
\hline Tumor size & 38.21 & 1.153 & $1.102-1.206$ & $<0.0001$ \\
\hline Operation method & 11.05 & & & 0.0040 \\
\hline Segmentectomy/partial resection & & 1 & Reference & \\
\hline Lobectomy & 2.039 & 1.437 & $0.874-2.358$ & 0.1533 \\
\hline Pneumonectomy & 10.26 & 1.686 & $1.224-2.320$ & 0.0014 \\
\hline Histology & 10.57 & & & 0.0143 \\
\hline Ad & & 1 & Reference & \\
\hline Sq & 3.864 & 0.808 & $0.653-0.999$ & 0.0493 \\
\hline La & 0.069 & 0.945 & $0.619-1.443$ & 0.7934 \\
\hline Others & 4.855 & 1.524 & $1.048-2.218$ & 0.0276 \\
\hline Pathologic stage & 175.0 & & & $<0.0001$ \\
\hline IA & & 1 & Reference & \\
\hline IB & 7.402 & 1.639 & $1.148-2.340$ & 0.0065 \\
\hline IIA & 24.36 & 3.238 & $2.031-5.163$ & $<0.0001$ \\
\hline IIB & 22.17 & 2.381 & $1.659-3.418$ & $<0.0001$ \\
\hline IIIA & 62.82 & 3.739 & $2.698-5.180$ & $<0.0001$ \\
\hline IIIB & 97.37 & 4.483 & $3.328-6.040$ & $<0.0001$ \\
\hline IV & 115.1 & 8.641 & $5.827-12.81$ & $<0.0001$ \\
\hline COPD grade & 21.34 & & & $<0.0001$ \\
\hline Non-COPD & & 1 & Reference & \\
\hline Mild COPD & 2.087 & 1.292 & $0.913-1.829$ & 0.1486 \\
\hline Moderate COPD & 0.156 & 1.049 & $0.827-1.331$ & 0.6931 \\
\hline Severe COPD & 20.23 & 2.774 & $1.778-4.328$ & $<0.0001$ \\
\hline
\end{tabular}

Abbreviations: Ad, adenocarcinoma; BMI, body mass index; $\mathrm{Cl}$, confidence interval; COPD, chronic obstructive pulmonary disease; La, large cell carcinoma; Sq, squamous cell carcinoma. 
there have been many reports that segmentectomy did not cause decreased survival benefit in stage IA lung cancer patients. $^{21,22}$ Especially in patients with severely compromised lung function, Griffin et al reported that wedge resection for stage I disease produced a survival rate similar to the rate for standard operation. ${ }^{23}$ This suggests that early detection of lung cancer and limited resection may lead to cure despite the presence of severe COPD.

This retrospective study has certain limitations and biases. First, some of the moderate-to-severe COPD patients could not undergo postoperative adjuvant therapy and additional therapy at the time of tumor recurrence because of poor cardiopulmonary reserve. This might have affected the prognosis. Volpino et al reported that moderate-to-severe COPD patients have increased risk for noncancer death due to cardiovascular or pulmonary causes. ${ }^{24}$ Second, COPD should not be defined by functional limitations only. Other factors, such as diffusion capacity, radiological findings, and clinical criteria should have been taken into consideration. ${ }^{25}$ It is possible that the use of other criteria for COPD could produce different results. Third, this was a small dataset from a singlecenter study, and there were small numbers of patients with mild and severe COPD. Therefore, there may be several confounding variables.

In conclusion, although COPD carries a high risk for postoperative complications and poor long-term survival, appropriate selection of operative method and careful perioperative management can provide a better than expected prognosis. Patients with severe COPD should be considered carefully with regard to indications for lung cancer surgery.

\section{References}

1 Brunelli A, Charloux A, Bolliger CT, et al; European Respiratory Society and European Society of Thoracic Surgeons joint task force on fitness for radical therapy. ERS/ESTS clinical guidelines on fitness for radical therapy in lung cancer patients (surgery and chemo-radiotherapy). Eur Respir J 2009;34(1):17-41

2 Colice GL, Shafazand S, Griffin JP, Keenan R, Bolliger CT; American College of Chest Physicians. Physiologic evaluation of the patient with lung cancer being considered for resectional surgery: ACCP evidenced-based clinical practice guidelines (2nd edition). Chest 2007;132(3 Suppl):161S-177S

3 Sekine Y, Kesler KA, Behnia M, Brooks-Brunn J, Sekine E, Brown JW. COPD may increase the incidence of refractory supraventricular arrhythmias following pulmonary resection for non-small cell lung cancer. Chest 2001;120(6):1783-1790

4 Licker MJ, Widikker I, Robert J, et al. Operative mortality and respiratory complications after lung resection for cancer: impact of chronic obstructive pulmonary disease and time trends. Ann Thorac Surg 2006;81(5):1830-1837

5 Sekine Y, Behnia M, Fujisawa T. Impact of COPD on pulmonary complications and on long-term survival of patients undergoing surgery for NSCLC. Lung Cancer 2002;37(1):95-101

6 López-Encuentra A, Astudillo J, Cerezal J, Gonzalez-Aragoneses F, Novoa N, Sánchez-Palencia A; Bronchogenic Carcinoma Cooperative Group of the Spanish Society of Pneumology and Thoracic Surgery (GCCB-S). Prognostic value of chronic obstructive pulmonary disease in 2994 cases of lung cancer. Eur J Cardiothorac Surg 2005;27(1):8-13
7 American Thoracic Society. Standards for the diagnosis and care of patients with chronic obstructive pulmonary disease. Am J Respir Crit Care Med 1995;152(5 Pt 2):S77-S121

8 Sekine Y, Yamada Y, Chiyo M, et al. Association of chronic obstructive pulmonary disease and tumor recurrence in patients with stage IA lung cancer after complete resection. Ann Thorac Surg 2007;84(3):946-950

9 Young RP, Hopkins RJ, Christmas T, Black PN, Metcalf P, Gamble GD. COPD prevalence is increased in lung cancer, independent of age, sex and smoking history. Eur Respir J 2009;34(2): 380-386

10 Wilson DO, Weissfeld JL, Balkan A, et al. Association of radiographic emphysema and airflow obstruction with lung cancer. Am J Respir Crit Care Med 2008;178(7):738-744

11 Congleton J, Muers MF. The incidence of airflow obstruction in bronchial carcinoma, its relation to breathlessness, and response to bronchodilator therapy. Respir Med 1995;89(4):291-296

12 Kurishima K, Satoh H, Ishikawa $\mathrm{H}$, et al. Lung cancer patients with chronic obstructive pulmonary disease. Oncol Rep 2001;8(1): 63-65

13 Sin DD, Anthonisen NR, Soriano JB, Agusti AG. Mortality in COPD: Role of comorbidities. Eur Respir J 2006;28(6):1245-1257

14 Cooper JD, Trulock EP, Triantafillou AN, et al. Bilateral pneumectomy (volume reduction) for chronic obstructive pulmonary disease. J Thorac Cardiovasc Surg 1995;109(1):106-116, discussion 116-119

15 Choong CK, Meyers BF, Battafarano RJ, et al. Lung cancer resection combined with lung volume reduction in patients with severe emphysema. J Thorac Cardiovasc Surg 2004;127(5):1323-1331

16 Benzo R, Farrell MH, Chang CC, et al; NETT Research Group. Integrating health status and survival data: the palliative effect of lung volume reduction surgery. Am J Respir Crit Care Med 2009;180(3):239-246

17 Fessler HE, Scharf SM, Ingenito EP, McKenna RJ Jr, Sharafkhaneh A. Physiologic basis for improved pulmonary function after lung volume reduction. Proc Am Thorac Soc 2008;5(4):416-420

18 Sekine Y, Iwata T, Chiyo M, et al. Minimal alteration of pulmonary function after lobectomy in lung cancer patients with chronic obstructive pulmonary disease. Ann Thorac Surg 2003;76(2):356361, discussion 362

19 Baldi S, Ruffini E, Harari S, et al. Does lobectomy for lung cancer in patients with chronic obstructive pulmonary disease affect lung function? A multicenter national study. J Thorac Cardiovasc Surg 2005;130(6):1616-1622

20 Ginsberg RJ, Rubinstein LV; Lung Cancer Study Group. Randomized trial of lobectomy versus limited resection for T1 N0 non-small cell lung cancer. Ann Thorac Surg 1995;60(3):615-622, discussion 622-623

21 Nakamura H, Kawasaki N, Taguchi M, Kabasawa K. Survival following lobectomy vs limited resection for stage I lung cancer: a meta-analysis. Br J Cancer 2005;92(6):1033-1037

22 Koike T, Yamato Y, Yoshiya K, Shimoyama T, Suzuki R. Intentional limited pulmonary resection for peripheral T1 N0 M0 small-sized lung cancer. J Thorac Cardiovasc Surg 2003;125(4):924-928

23 Griffin JP, Eastridge CE, Tolley EA, Pate JW. Wedge resection for non-small cell lung cancer in patients with pulmonary insufficiency: prospective ten-year survival. J Thorac Oncol 2006;1(9): 960-964

24 Volpino P, Cangemi R, Fiori E, et al. Risk of mortality from cardiovascular and respiratory causes in patients with chronic obstructive pulmonary disease submitted to follow-up after lung resection for non-small cell lung cancer. J Cardiovasc Surg (Torino) 2007;48(3):375-383

25 Celli BR, Halbert RJ, Isonaka S, Schau B. Population impact of different definitions of airway obstruction. Eur Respir J 2003;22 (2):268-273 